OPEN ACCESS

Edited by:

Madhu S. Dhar,

The University of Tennessee, Knoxville,

United States

Reviewed by:

Francisco Miguel Sanchez Margallo, Centro de Cirugía de Mínima Invasión

Jesús Usón, Spain Marco Patruno,

University of Padua, Italy

*Correspondence:

Anna Lange-Consiglio

anna.langeconsiglio@unimi.it

Specialty section:

This article was submitted to

Veterinary Regenerative Medicine,

a section of the journal

Frontiers in Veterinary Science

Received: 17 April 2020

Accepted: 06 July 2020

Published: 13 August 2020

Citation:

Cremonesi F, Bonfanti S, Idda A and Lange-Consiglio A (2020) Platelet Rich

Plasma for Regenerative Medicine

Treatment of Bovine Ovarian

Hypofunction. Front. Vet. Sci. 7:517.

doi: 10.3389/fvets.2020.00517

\section{Platelet Rich Plasma for Regenerative Medicine Treatment of Bovine Ovarian Hypofunction}

\author{
Fausto Cremonesi ${ }^{1}$, Stefano Bonfanti ${ }^{2}$, Antonella Idda ${ }^{1}$ and Anna Lange-Consiglio ${ }^{1 *}$ \\ ${ }^{1}$ Dipartimento di Medicina Veterinaria, Università degli Studi di Milano, Milan, Italy, ${ }^{2}$ Private Practitioner, Milan, Italy
}

Recent studies on cull cows have shown that ovarian abnormalities, particularly ovarian insufficiency, are the main cause of reproductive failure. The aim of this study was to treat bovine ovarian failure with intraovarian administration of autologous platelet rich plasma (PRP), which is rich in growth factors, chemokines, and cytokines that could stimulate follicular growth and steroidogenesis. Twelve cows with ovarian hypofunction were enrolled in the study and they were randomly allocated in control group (CTR) and treated group (six animal for group). In the treated group, only five animals received the PRP treatment because intraovarian administration was hindered in one by a rectovaginal fistula. Animals of control group were treated by intraovarian administration of physiological solution. In the 4 weeks after PRP injection, a mild to strong increase in progesterone (PRG) concentrations was detected in four of the five cows treated. Artificial insemination (Al) resulted in four pregnancies that are still ongoing (7th month). Intraovarian administration of PRP improved ovarian function after 2 months of treatment. This effect may be due to reduction of follicular atresia or to revitalization of dormant oocytes allowing restoration of fertility.

Keywords: bovine, ovarian hypofunction, platelet rich plasma, progesterone, growth factors

\section{INTRODUCTION}

In recent years, the decline in fertility is negatively related to the increase in milk production in dairy cattle and it is common worldwide. Indeed, to date there is a large scientific literature on the sub-fertility of dairy cows (1). Recent studies showed that the main causes for low fertility in dairy cows are reproductive disorders (2), mainly due to ovarian abnormalities. There are different kind of ovarian disorders such as ovarian hypofunction, cystic ovarian disease, sub-oestrus, or silent ovulation, and sub-luteal function. Although all ovarian disorders have an impact on profits, and are a challenge for the dairy manager, this paper focuses on ovarian hypofunction and ovarian failure. Within the different ovarian disorders, ovarian failure is the most common ovarian disorder (11.45\%) compared to cysts and adhesions (5.22 and 6.38\%, respectively) (3).

Ovarian hypofunction is determined by the presence of follicles with a diameter of at least $8-15 \mathrm{~mm}$ visible in two consecutive examinations, by the absence of a corpus luteum or cysts without signs of oestrus in the 7-day period between the examinations (4).

During the bovine oestrous cycle, the development of antral follicle occurs through two or three waves of follicular growth $(5,6)$. Follicles of 3-4 $\mathrm{mm}$ diameter grow to about 6-8 $\mathrm{mm}$ in diameter. When the largest follicle reaches a diameter of $8.5 \mathrm{~mm}$ (7), it begins its follicular dominance that determines its size increment and the arrest of the smaller subordinate follicles. The dominant 
follicle will become the ovulatory follicle (8) and the luteinizing hormone $(\mathrm{LH})$ appears to regulate its function $(9,10)$.

Rapid LH pulse frequency (1 pulse/15-20 min) is correlated with the maturation and ovulation of the dominant follicle, on the contrary, slow LH pulse frequency ( 1 pulse/3-5h) results in follicular atresia (11).

Ovarian hypofunction can be related to intermediate $\mathrm{LH}$ frequencies ( 1 pulse every $1-2 \mathrm{~h}$ ) due to different factors such as low progesterone concentrations or heat stress (1). Usually, these cows have a follicle of at least $8-15 \mathrm{~mm}$ and absence of cysts or luteal structures on two consecutive examinations during the postpartum period, so it can be assumed that most cows affected by ovarian hypofunction have ovarian anovulation.

Currently, these cows would be treated with gonadotropin releasing hormone $(\mathrm{GnRH})$-based treatments such as the Ovsynch protocol $(4,12,13)$ or a progesterone releasing intravaginal device (PRID) (14), but oestrus response in affected cows is very low (usually $<30 \%$ ). There is clearly a need for better reproductive strategies to reduce the economic impact of decreased fertility. These strategies should increase the amount of cyclic cows and the effectiveness of oestrus detection but most importantly, improve ovarian function and completion of follicle growth. Since the blocking of follicular growth results in a low positive feedback to the hypothalamus, an alternative strategy for treatment of ovarian failure could be an administration of regenerative elements directly into the ovary, with the aim of stimulating follicular growth and, consequently, steroidogenesis in turn stimulating gonadotropin (FSH and $\mathrm{LH}$ ) secretion.

This study proposes a novel therapeutic approach for treatment of ovarian failure based on the regenerative properties of PRP already well-documented in human $(15,16)$ and veterinary $(17,18)$ medicine.

\section{MATERIALS AND METHODS}

The in vivo animal study was approved by the Milan University Bioethics Committee n.118_2017, in accordance with 2010/63 EU directive on animal protection and Italian Law (D.L. No. 116/1992) and following standard veterinary practice. An authorization number $658 / 2020$-PR of the Italian ministry of health has also been obtained. Written informed consent from the owners was also obtained to allow evaluation of the in vivo effects of PRP in cows with ovarian failure.

\section{Study Design}

To investigate the effect of PRP in restoring ovarian function in cows with ovarian failure, the study was divided into two parts: (1) in vitro production of PRP; (2) in vivo intraovarian PRP administration.

Abbreviations: AI, artificial insemination; EGF, epidermal growth factor; FGF, fibroblast growth factor; GnRH, gonadotropin realizing hormone; HGF, hepatocyte growth factor; IGF-I, insulin-like growth factor 1; LH, luteinizing hormone; PDGFAA, PDGF-BB, PDGF-AB, platelet derived growth factors; PRG, progesterone; PRID, progesterone releasing intravaginal device; PRP, platelet rich plasma; TGF- $\beta 1$, transforming growth factor $\beta 1$; TGF- $\beta 2$, transforming growth factor $\beta 2$; VEGF, vascular endothelial growth factor.

\section{In vitro Production of PRP}

Homologous platelet rich plasma was prepared from blood collected from animals enrolled in the study. To produce PRP, the blood was processed as described by Lange-Consiglio et al. (17). Briefly: the site of blood collection was the subcutaneous mammary vein. Blood ( $450 \mathrm{ml}$ ) was collected in ad hoc Terumo blood bags (Terumo Srl, Rome, Italy), containing CPDA- 1 and transported at $+4^{\circ} \mathrm{C}$ to the laboratory to be immediately processed.

In aseptic conditions, the blood was drawn into sterile $50 \mathrm{ml}$ Falcon tubes (Euroclone, Milan, Italy) and centrifuged at $100 \times$ $\mathrm{g}$ for $30 \mathrm{~min}$. The result of centrifugation was the separation of the blood into three components: red blood cells at the lowest level, "buffy coat" in the middle layer, and platelet-rich plasma (PRP) in the upper layer. The PRP was aspirated and centrifuged again at $1,500 \times \mathrm{g}$ for $10 \mathrm{~min}$ to obtain a platelet pellet and the platelet poor plasma (PPP). The pellet was mixed in a PPP volume to obtain a PRP at a standard concentration of $1 \times 10^{9}$ platelet $/ \mathrm{ml}$. All platelet counts on peripheral blood and PRP were performed by an automatic hematology analyzer HeCo Vet SEAC (Florence, Italy).

The total volume of PRP obtained from each animal was stored in syringes ready-to-use. The syringes were frozen at $-80^{\circ} \mathrm{C}$ and thawed three times at $37^{\circ} \mathrm{C}$ (19) to allow the release of platelet derived factors. Syringes containing the dose of $5 \mathrm{ml}$ of PRP were kept frozen at $-80^{\circ} \mathrm{C}$ until use. The PRP was subjected to bacteriological examination to verify its sterility.

\section{In vivo Intraovarian PRP Administration Animals}

Animals enrolled in this study belonged to the same livestock and their welfare conditions (related to housing, feeding, and watering) were identical to those of the remaining animals of the same farm.

This farm had an endowment of about 1,500 animals, with a conception rate of $32 \%$ and pregnant rate of $19 \%$. The ovarian hypofunction affected about $10 \%$ of adult cows and, usually, it was treated with the Ovsynch protocol with oestrus response about of $25 \%$. The average milk production of farm was of $34 \mathrm{l} /$ die while the average of the animals affected by ovarian hypofunction was of $38 \mathrm{l} /$ die. The animal affected by this pathology were more productive of the other animals.

Twelve Holstein-Friesian cows, 2-3 years old, with no oestrus signs after the voluntary waiting period for breeding (around 60 days), were monitored via cow podometers for two oestrus cycles before being diagnosed as anoestrus. Ultrasound examination (SonoSite Portable ultrasound with a $5.0 \mathrm{MHz}$ linear-array transducer, Inc, USA) confirmed bilateral ovarian failure for all the subjects enrolled in the study. The animals were randomly allocated in treated group with intraovarian administration of PRP and in control group (CTR) with intraovarian administration of placebo to confirm that the needle does not cause trauma to the ovary. Each group was composed of six animals. 


\section{Setting}

In this farm, the lactating cows were housed in bunks with a concrete floor but with the availability of clean straw. The barn was clean, airy, well lit, with shaded areas, fans, and watering facilities. An automatic control system was used to remove dung four times a day (at $6.00,11.00,18.00$, and $23.00 \mathrm{~h}$ ). Lactating cows were fed twice a day during the experiment period (at 5.00 and $16.00 \mathrm{~h}$ ) and received total mixed ration composed of medical bandaged, medical dry, soybean flour, barley, cotton, and cornmeal. This mixed ration was supplemented with milk and silage. Mineral salt and water were provided ad libitum.

\section{Intraovarian Injection of PRP or Placebo}

In the treated group animal, the intraovarian PRP injection was performed under ultrasound guidance using a Madison SA $600 \mathrm{v}$ instrument equipped with an ovum pick up probe (PB06VE65/20BD) as described by Cremonesi et al. (20). Each animal was restrained in a cattle cage and clipped over the S5$\mathrm{C} 1$ vertebrae $(5 \times 5 \mathrm{~cm})$. The area was cleaned three times with alcohol and povidone-iodine. Then, sacrococcygeal (SC) epidural anesthesia was induced with $4 \mathrm{ml}$ of Procaine hydrochloride $2 \%$ (Procamidor, Richter Pharma Ag) and confirmed by loss of tail tone. Before introduction of the ultrasound probe into the vaginal fornix, the vulva was cleaned and the vagina lubricated. The ovary was manually directed to the probe by rectal palpation. A spinal $18 \mathrm{G}$ needle connected to a steel tube was inserted into the probe needle guide and passed through the fornix to enter the ovarian stroma to administer the PRP. Five cows received $5 \mathrm{ml}$ of $\mathrm{PRP}$ with a concentration of $1 \times 10^{9}$ platelet $/ \mathrm{ml}$ in each ovary. A rectovaginal fistula in the sixth cow prevented access to the ovaries and no PRP was administered in this cow.

The dose of PRP administered was calculated following the procedures of Pantos et al. (21) and by tests carried out in our laboratory with bovine ovaries recovered at the slaughterhouse.

In the control animal, the ovaries were injected with $5 \mathrm{ml}$ of placebo (physiological solution: $0.9 \% \mathrm{NaCl}$ ) with the same protocol of treated animals.

\section{Data Measurement}

A blood sample $(10 \mathrm{ml})$ was collected from the tail vein of each cow before PRP or placebo treatment (week 0) to measure progesterone (PRG) concentrations. Blood analysis was repeated after 2 and 4 weeks of treatment. The blood was refrigerated at $4{ }^{\circ} \mathrm{C}$ for $30 \mathrm{~min}$. The upper serum was then collected by centrifugation for $10 \mathrm{~min}(3,000 \times \mathrm{g})$ and placed in $\mathrm{a}-80^{\circ} \mathrm{C}$ freezer. The plasma concentration of progesterone was assessed using a quantitative automated method based on the enzyme-linked fluorescent assay (ELFA) technique (Mini-Vidas; bioMérieux Italia S.p.A., Florence, Italy).

In the weeks following treatment, ovaries were monitored by ultrasound and follicles or corpus luteum were detected in all treated cows (Figure 1) but not in control animals.

Breeding experiments were performed when animals were detected in oestrus. Artificial insemination, with cryopreserved semen thawed for $30 \mathrm{~s}$ at $36-37^{\circ} \mathrm{C}$ and evaluated for quality was performed at $8-12 \mathrm{~h}$ after signs of oestrus. Frozen semen from the same bull of proven fertility was used for artificial insemination (AI) in all cows.

Pregnancy diagnosis was performed by ultrasound at 38,56 , and 120 days.

The timeline of the study is shown in Figure 2.

\section{Statistical Methods}

Progesterone concentration data were analyzed with RStudio Version 1.2.1335. Data normality was evaluated with ShapiroWilk Normality Test. For non-normally distributed data, Kruskal-Wallis non-parametric test was used. Differences were considered statistically significant when $p \leq 0.05$.

\section{RESULTS}

Only five animals of treated group were treated with intraovarian administration of PRP because a rectovaginal fistula in one cow prevented access to the ovaries.

In the 4 weeks after PRP injection, a mild to strong increase in progesterone concentration was detected in four of the five cows treated (Table 1). No variation in progesterone concentration was detected in CTR animals (Table 2).

After 4 weeks, in cow number 70 the progesterone increased 4.8 fold (from 0.89 to $4.27 \mathrm{ng} / \mathrm{ml}$ ). In cow 175 , the increase was 11 fold (from 0.32 to $3.54 \mathrm{ng} / \mathrm{ml}$ ). In cow 424, the progesterone concentration remained unchanged $(0.45-0.58 \mathrm{ng} / \mathrm{ml})$. In cow 438 , the progesterone increased 3.33 fold $(1.87-6.23 \mathrm{ng} / \mathrm{ml})$ and in cow 1,078 , there was a 3.97 fold increase $(1.2-4.76 \mathrm{ng} / \mathrm{ml})$.

Despite the numerical increases, there were no statistically significant differences $(p>0.05)$ in progesterone concentrations between week 0 and 4 .

In four cows in which PRP administration was followed by an increase in progesterone concentration, AI resulted in a pregnancy that is still going (7th month) (Figure 3, diagnosis at 38 days).

\section{DISCUSSION}

This study describes the administration of intraovarian PRP to treat cows diagnosed with ovarian failure at the end of the voluntary waiting period after their last parturition. One cow was excluded from the study due to a rectovaginal fistula that hindered the PRP injection.

The rational for application of PRP to hypo-functional ovaries comes from its known properties in regenerative medicine. Indeed, PRP is mainly used in human medicine to accelerate the healing process following surgery (for example maxillofacial surgery), in the repair of muscle and/or tendon, and in the reversal of skin ulcers (16). In veterinary medicine, the therapeutic use of PRP is still very limited. It has been mainly used to promote equine tendon repair (22), to treat intestinal wound healing in pigs (23), to cure a large cutaneous lesion in a dog (24), in bovine mastitis (17) and in repeat breeder cows (18). In all cases, PRP showed a clear regenerative potential due to its amount of growth factors with mitogenic and anti-inflammatory potential $(16,25)$. In particular, this hematic product can be defined PRP only if it has a platelet concentration 3-5 fold higher 
A
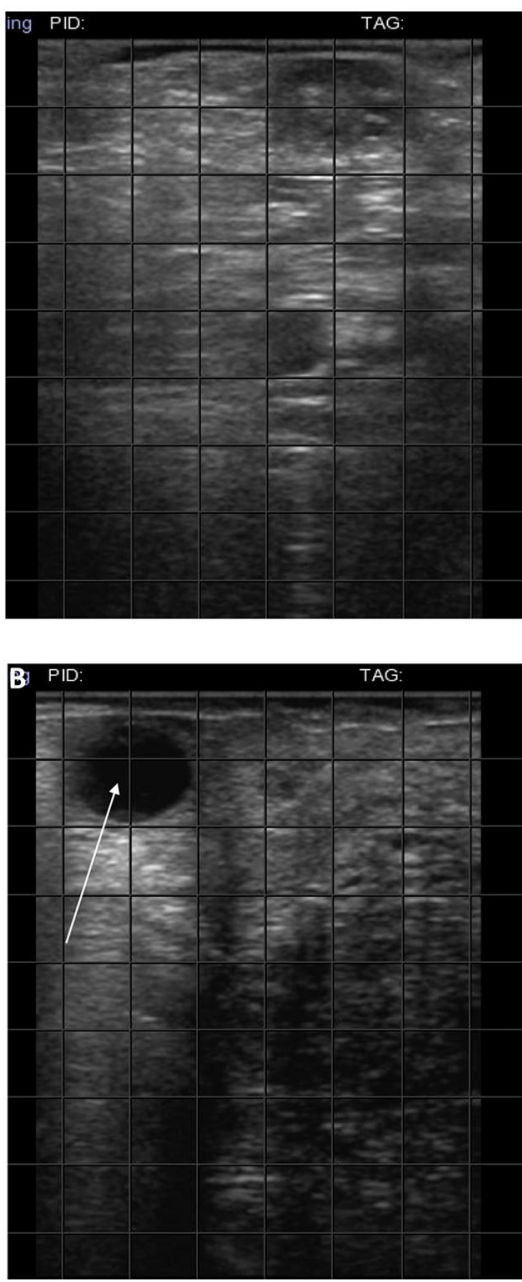
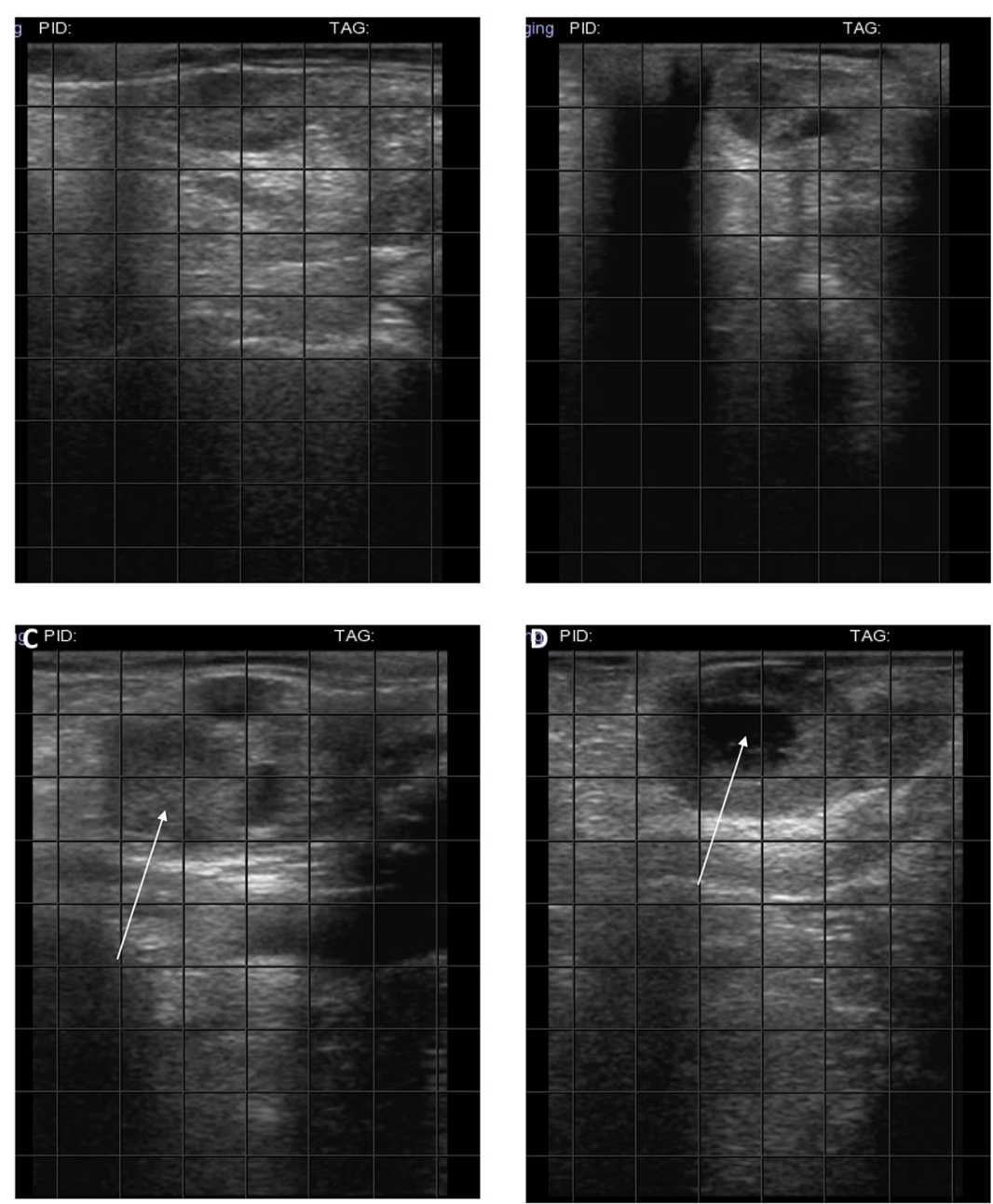

FIGURE 1 | Ultrasound of ovaries. (A) Hypogonadal ovaries; (B) the arrow indicates $2 \mathrm{~cm}$ follicles; (C) the arrow indicates a corpus hemorrhagicum; (D) the arrow indicates a corpus luteum

than the physiological level. The PRP contains several growth factors including the transforming growth factor $\beta 1$ (TGF$\beta 1$ ) and TGF- $\beta 2$, platelet derived growth factors (PDGFAA, PDGF-BB, and PDGF-AB), insulin-like growth factor 1 (IGFI), epidermal growth factor (EGF), vascular endothelial growth factor (VEGF), fibroblast growth factor (FGF), and hepatocyte growth factor (HGF). All these factors, which are stored in the $\alpha$-granules, are very important in the regeneration process. The $\alpha$-granules release their content following their breakdown which can occur physically by temperature excursion (19) or by induced platelet activation (26).

The regenerative effect of PRP in the reproductive field was first muted by the Pantos group, which was able to stimulate ovarian rejuvenation and obtain livebirths in perimenopausal women with infertility (27). These promising results were expanded by Sills et al. (28), who performed intraovarian administration of PRP in a clinic setting, without anesthesia, using transvaginal ultrasound guidance, and confirmed by Pantos et al. (21). These studies reported an increase in serum AMH, decrease in FSH, fertilization via intracytoplasmic sperm injection of collected oocytes, and generated blastocysts suitable for banking or immediate embryo transfer. Pregnancies were also reported $(21,28)$. The impact of PRP in treating human reproductive disorders is also reported in some papers describing its positive effect after intrauterine administration in patients with repeated implantation failure (28) and chronic endometritis (29).

In the veterinary field, a study performed by our team showed that PRP induced an increase in progesterone receptors after in vivo uterine administration in healthy cows and exerted a modulatory effect on a range of molecules involved in inflammation, which resulted in an anti-inflammatory effect in an in vitro endometritis model (30).

During development, the ovary faces a variety of changes and remodeling. The process of follicular growth begins from the original oocyte that derived from primordial germ cells (31). During embryogenesis, the ovarian cells of the female fetus are delimited by granulosa cells to form primordial follicles (32). 


\section{Oestrus monitoring with cow pedometer}
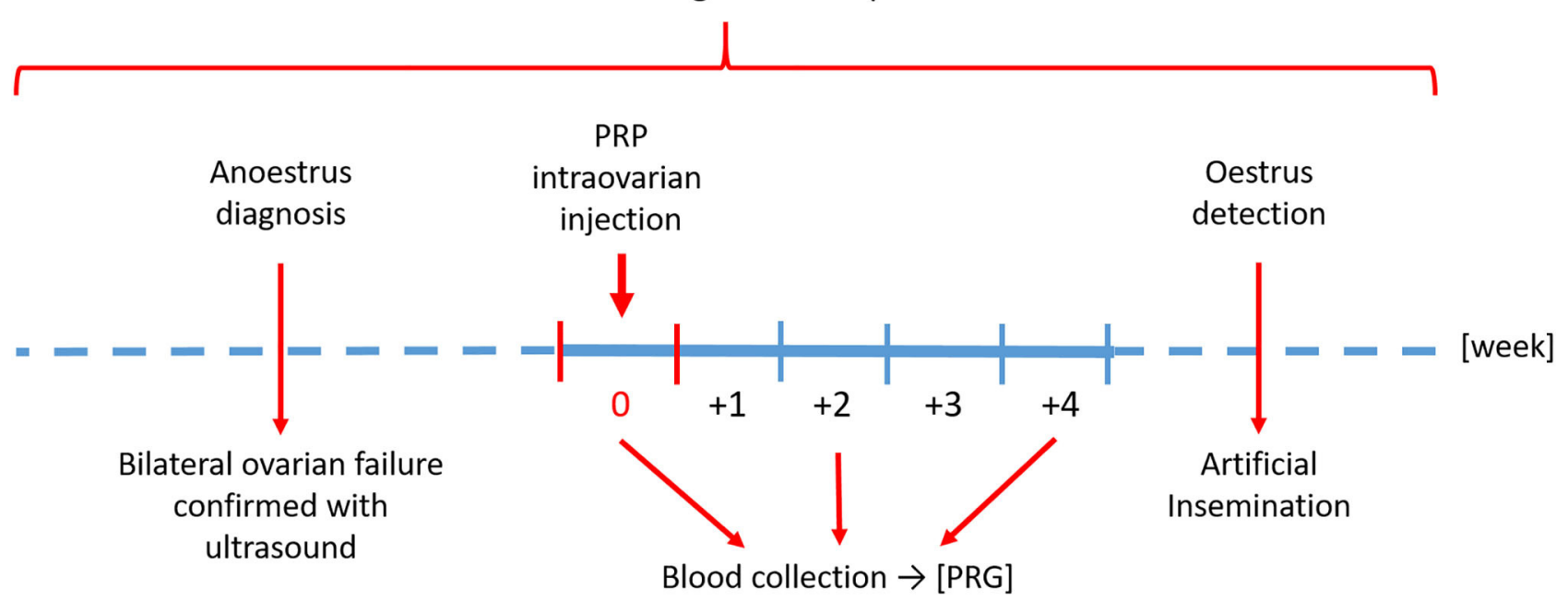

FIGURE 2 | Timeline of the study.

TABLE 1 | Dataset showing identification information for each treated cow enrolled in the study (ID, age, lactation) and progesterone concentration and pregnancy detection after intraovarian PRP injection.

\begin{tabular}{lcccccc}
\hline Cow ID & $\begin{array}{c}\text { Age } \\
\text { (years) }\end{array}$ & $\begin{array}{c}\mathbf{N}^{\circ} \\
\text { lactation }\end{array}$ & \multicolumn{2}{c}{$\begin{array}{c}\text { Progesterone concentration } \\
\text { (ng/ml) }\end{array}$} & $\begin{array}{c}\text { Pregnancy } \\
\text { after PRP } \\
\text { treatment }\end{array}$ \\
\cline { 4 - 6 } & & & week0 & week+2 & week+4 & \\
\hline 70 & 3 & 2 & 0.89 & 1.57 & 4.27 & Yes \\
175 & 2 & 1 & 0.32 & 0.31 & 3.54 & Yes \\
424 & 4 & 3 & 0.45 & 2.63 & 0.58 & No \\
438 & 3 & 2 & 1.87 & 1.14 & 6.23 & Yes \\
779 & 5 & 4 & Not treated because of rectovaginal fistula \\
1,078 & 2 & 1 & 1.2 & 5.67 & 4.76 & Yes
\end{tabular}

TABLE 2 | Dataset showing identification information for each control cow enrolled in the study (ID, age, lactation) and progesterone concentration and pregnancy detection.

\begin{tabular}{|c|c|c|c|c|c|c|}
\hline \multirow[t]{2}{*}{ Cow ID } & \multirow[t]{2}{*}{$\begin{array}{c}\text { Age } \\
\text { (years) }\end{array}$} & \multirow[t]{2}{*}{$\begin{array}{c}\mathrm{N}^{\circ} \\
\text { lactation }\end{array}$} & \multicolumn{3}{|c|}{$\begin{array}{l}\text { Progesterone concentration } \\
\qquad(\mathrm{ng} / \mathrm{ml})\end{array}$} & \multirow[t]{2}{*}{ Pregnancy } \\
\hline & & & week0 & week +2 & week +4 & \\
\hline 321 & 2 & 1 & 0.47 & 0.65 & 0.82 & No \\
\hline 267 & 2 & 1 & 0.45 & 0.75 & 0.69 & No \\
\hline 643 & 3 & 2 & 0.37 & 0.66 & 0.84 & No \\
\hline 185 & 4 & 3 & 0.77 & 1.03 & 0.82 & No \\
\hline 482 & 3 & 2 & 0.86 & 0.66 & 0.49 & No \\
\hline 947 & 3 & 2 & 0.49 & 0.79 & 0.85 & No \\
\hline
\end{tabular}

Granulosa cells are necessary during follicular development (33, 34) and follicular atresia is probably mainly caused by granulosa cell apoptosis.

Presumably, the PRP effect on ovarian dysfunction is due to secretion of nutritional factors that produce beneficial effects on follicles. To date, the mechanism of action on the ovary is not entirely clear, but there are two main hypothesis that refer to ovarian reserve. It is well-known that, at birth, the mammalian female has a fixed ovarian that is dormant and closed in primary follicles until the moment of activation, when growth and meiotic occur. The first hypothesis suggests that growth factors and cytokines in PRP act on dormant oocytes exerting a revitalizing effect and restoring fertility (28).

The other hypothesis supports the existence of ovarian germ cells from which would be generated new oocytes (28). The existence of ovarian stem cell and the detailed study of the mechanisms underlying the PRP action is worthy of further study, but goes beyond the scope of our preliminary work in this animal model.

This study focused on empirical assessment of the efficacy of PRP through measurement of progesterone (PRG) levels as a marker for restored ovarian cycling and the monitoring of oestrus to perform AI. Data reported in this study are certainly limited but do support recent reports on the capacity to restore physiological function of a malfunctioning ovary using PRP.

In particular, our data show that after intraovarian PRP injection (week 0), the level of PRG increased between 3 and 11 fold during the subsequent 4 weeks (Table 1). This increase in PRG concentration indicates recovery of ovarian cycling. Presumably, in light of the large changes in PRG measured, each cow had more than one ovulation during those 4 weeks. Artificial insemination was performed when oestrus monitoring signaled the heat. Artificial insemination was needed on more than one occasion to obtain a pregnancy. As indicated in the right column of Table 1, the time between PRP injection and the detection of pregnancy varied for each cow and depended on the success of AI. Pregnancy occurred only in the four cows that experienced increased PRG levels. Only one animal failed to respond to PRP treatment. Further studies including larger numbers of cows are required in future studies.

No analysis of serum AMH or FSH levels was performed. This could have added more accurate information on the temporal 

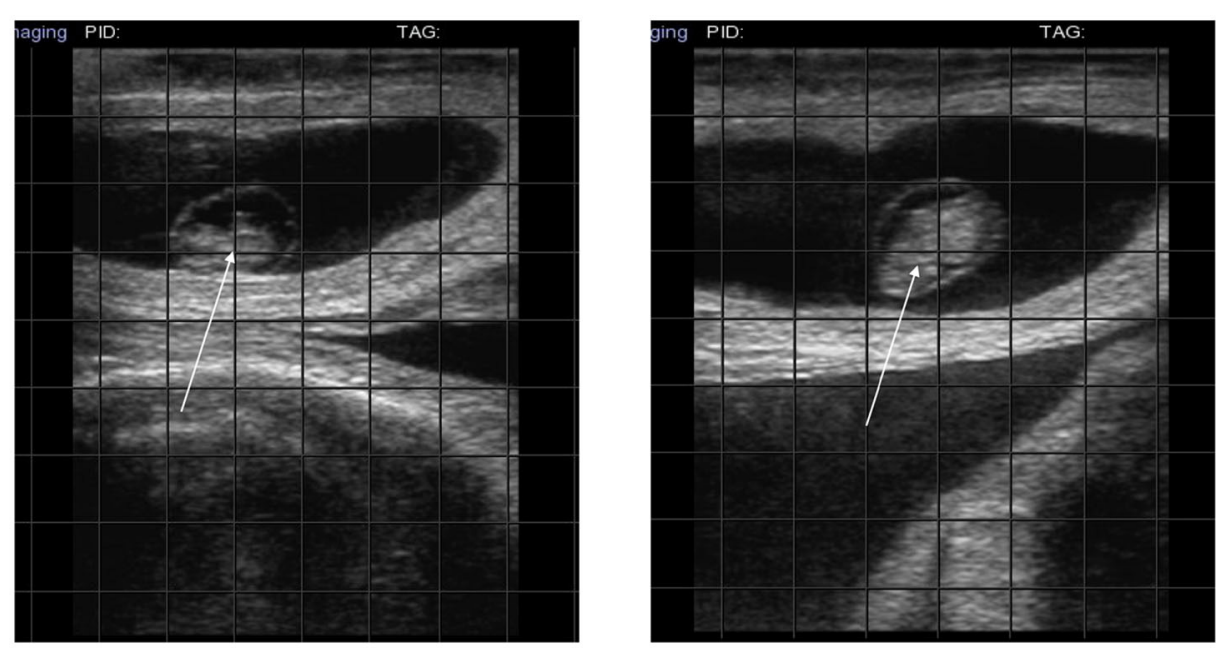

FIGURE 3 | Ultrasound at 38 day. The arrows indicate the embryo confirming pregnancy.

changes in the cows' hormonal status but it is likely that a rise in PRG corresponds to a decrease in FSH whilst, to date, there are conflicting reports on the variable levels of $\mathrm{AMH}$ in literature (35).

Usually, in this farm, the hypogonadism affects the $10 \%$ of animals that are treated with the Ovsynch protocol, with oestrus response about of $25 \%$. In our study, we had performed a different control group with intra-ovarian administration of placebo to confirm that it was not the trauma caused by the needle that awakened the ovarian activity but really the PRP. In our opinion, the main platelet-derived mediators in improving ovarian could be the PDGF, the TGF- $\beta$, and the HGF because all these growth factors have mitogenic or trophic effects and, specifically, the TGF- $\beta$ that can stimulate cell proliferation and differentiation. In this moment, it is no possible to affirm that the ovarian activity is restored in the long time by PRP because the four treated cows are pregnant and only after the delivery and the voluntary waiting period for breeding, the oestrus signs will be evaluated to confirm the efficacy of PRP in this pathology.

\section{CONCLUSIONS}

This is the first report of successful pregnancies after PRP intraovarian injection in cows with ovarian failure. These findings support the use of PRP in clinical practice, supplement the literature regarding the use of PRP in a reproductive context, and motivate the study of the fine mechanisms underlying PRP action.

\section{DATA AVAILABILITY STATEMENT}

The raw data supporting the conclusions of this article will be made available by the authors, without undue reservation.

\section{ETHICS STATEMENT}

The animal study was reviewed and approved by Milan University Bioethics Committee no. 118_2017 and by authorization number $658 / 2020-\mathrm{PR}$ of the Italian ministry of health. Written informed consent was obtained from the owners for the participation of their animals in this study.

\section{AUTHOR CONTRIBUTIONS}

FC: conceptions and design, in vivo study with administration of PRP, evaluation of outcomes, interpretation of data, and final approval of manuscript. SB: in vivo study with administration of PRP, evaluation of outcomes, interpretation of data, and final approval of manuscript. AI: preparation of PRP, analysis and interpretation of data, and final approval of manuscript. AL-C: conceptions and design, preparation of PRP, coordination of all experiments, collection and assembly of all data, analysis and interpretation of data, manuscript writing, and final approval of manuscript. All authors contributed to the article and approved the submitted version.

\section{FUNDING}

This study was supported by Università degli Studi di Milano, Milano Italy.

\section{ACKNOWLEDGMENTS}

We thank the Università degli Studi di Milano and the owners of the cows for making them available to this study. 


\section{REFERENCES}

1. Dobson H, Smith RF. What is stress and how it affects reproduction. Anim Reprod Sci. (2000) 60-61:743-52. doi: 10.1016/S0378-4320(00)00080-4

2. Lopez-Gatius F, García-Ispierto I, Santolaria P, Yániz J, Nogareda C, López-Béjar M. Screening for high fertility in high-producing dairy cows. Theriogenology. (2006) 65:1678-89. doi: 10.1016/j.theriogenology.2005.09.027

3. Mekibib B, Desta T, Tesfaye D. Gross pathological changes in the reproductive tracts of cows slaughtered at two abattoirs in Southern Ethiopia. J Vet Med Anim Health. (2013) 5:46-50. doi: 10.5897/JVMAH12.060

4. Lopez-Gatius F, Santolaria P, Yani, J, Rutllant J, Lopez-Bejar M. Persistent ovarian follicles in dairy cows: a therapeutic approach. Theriogenology. (2001) 56:649-59. doi: 10.1016/S0093-691X(01)00596-9

5. Ginther OJ, Kastelic JP, Knopf L. Composition and characteristics of follicular waves during the bovine estrus cycle. Anim Reprod Sci. (1989) 20:187-200. doi: 10.1016/0378-4320(89)90084-5

6. Adams GP, Jaiswal R, Singh J, Malhi P. Progress in understanding ovarian follicular dynamics in cattle. Theriogenology. (2008) 69:72-80. doi: 10.1016/j.theriogenology.2007.09.026

7. Ginther OJ. Selection of the dominant follicle in cattle and horses. Anim Reprod Sci. (2000) 60-61:61-79. doi: 10.1016/S0378-4320(00)00083-X

8. Kastelic JP, Ginther OJ. Factors affecting the origin of the ovalatory follicle in heifers with induced luteolysis. Theriogenology. (1991) 37:1163-83.

9. Savio JD, Keenan L, Boland MP, Roche JF. Pattern of growth of dominant follicles during the oestrous cycle of heifers. J Reprod Fert. (1988) 83:663-71. doi: 10.1530/jrf.0.0830663

10. Sirois J, Fortune JE. Ovarian follicular dynamics during the estrous cycle in heifers monitored by real-time ultrasonography. Biol Reprod. (1988) 39:30817. doi: 10.1095/biolreprod39.2.308

11. Stock AE, Fortune JE. Ovarian follicular dominance in cattle: relationship between prolonged growth of the ovulation follicle and endocrine parameters. Endocrinology. (1993) 132:1108-14. doi: 10.1210/endo.132.3.8440173

12. Lopez-Gatius F, Murugavel K, Santolaria P, Lopez-Bejar M, Yaniz J. Pregnancy rate after timed artificial insemination in early post-partum dairy cows after Ovsynch or specific synchronization protocols. J Vet Med A. (2004) 51:33-8. doi: 10.1111/j.1439-0442.2004.00594.x

13. Yaniz JL, Murugavel K, Lopez-Gatius F. Recent developments in oestrous synchronization of postpartum dairy cows with and without ovarian disorders. Reprod Domest Anim. (2004) 39:86-93. doi: 10.1111/j.1439-0531.2004.00483.x

14. Yaniz JL, Lopez-Gatius F, Bech-Sabat G, Garcia-Ispierto I, Serrano B, Santolaria P. Relationships between milk production, ovarian function and fertility in high-producing dairy herds in north-eastern spain. Reprod Domest Anim. (2008) 43(Suppl. 4):38-43. doi: 10.1111/j.1439-0531.2008.01227.x

15. Bendinelli P, Matteucci E, Dogliotti G, Corsi MM, Banfi G, Maroni P, et al. Molecular basis of anti-inflammatory action of platelet-rich plasma on human chondrocytes: mechanisms of NF-кB inhibition via HGF. J Cell Physiol. (2010) 225:757-66. doi: 10.1002/jcp.22274

16. Anitua E, Andia I, Ardanza B, Nurden P, Nurden AT. Autologous platelets as a source of proteins for healing and tissue regeneration. Thromb Haemost. (2004) 91:4-15. doi: 10.1160/TH03-07-0440

17. Lange-Consiglio A, Spelta C, Garlappi R, Luini M, Cremonesi F. Intramammary administration of platelet concentrate as an unconventional therapy in bovine mastitis: first clinical application. J Dairy Sci. (2014) 97:1-8. doi: $10.3168 /$ jds.2014-7999

18. Lange Consiglio A, Cazzaniga N, Garlappi R, Spelta C, Pollera C, Perrini C, et al. Platelet concentrate in bovine reproduction: effects on in vitro embryo production and after intrauterine administration in repeat breeder cows. Reprod Biol Endocrinol. (2015) 13:65. doi: 10.1186/s12958-015-0064-6

19. Zimmermann R, Arnold, D, Strasser E, Ringwald J, Schlegel A, et al. Sample preparation technique and white cell content influence the detectable levels of growth factors in platelet concentrates. Vox Sang. (2003) 85:283-9. doi: 10.1111/j.0042-9007.2003.00361.x

20. Cremonesi F, Bonfanti S, Idda A, Lange-Consiglio A. Improvement of embryo recovery in holstein cows treated by intra-ovarian platelet rich plasma before superovulation. Vet Sci. (2020) 7:16. doi: 10.3390/vetsci7010016
21. Pantos K, Simopoulou M, Pantou A, Rapani A, Tsioulou P, Nitsos $\mathrm{N}$, et al. A case series on natural conceptions resulting in ongoing pregnancies in menopausal and prematurely menopausal women following platelet-rich plasma treatment. Cell Transpl. (2019) 28:1333-40. doi: 10.1177/0963689719859539

22. Rindermann G, Cislakova M, Arndt G, Carstanjen B. Autologous conditioned plasma as therapy of tendon and ligament lesions in seven horses. J Vet Sci. (2010) 11:173-5. doi: 10.4142/jvs.2010.11.2.173

23. Fresno L, Fondevila D, Bambo O, Chacaltana A, García F, Andaluz A. Effects of platelet-rich plasma on intestinal wound healing in pigs. Vet J. (2010) 185:322-7. doi: 10.1016/j.tvjl.2009.06.009

24. Kim JH, Park C, Park HM. Curative effect of autologous platelet-rich plasma on a large cutaneous lesion in a dog. Vet Dermatol. (2009) 20:123-6. doi: 10.1111/j.1365-3164.2008.00711.x

25. Gentile P, Orlandi A, Scioli MG, Di Pasquali C, Bocchini I, Cervelli V. Concise review: adipose-derived stromal vascular fraction cells and platelet-rich plasma: basic and clinical implications for tissue engineering therapies in regenerative surgery. Stem Cells Transl Med. (2012) 1:230-6. doi: 10.5966/sctm.2011-0054

26. Sills ES, Wood SH. Autologous activated platelet-rich plasma injection into adult human ovary tissue: molecular mechanism, analysis, and discussion of reproductive response. Biosci Rep. (2019) 39:1-15. doi: 10.1042/BSR2 0190805

27. Pantos K, Nitsos N, Kokkali G, Vaxevanoglou T, Markomichali C, Pantou A, et al. Ovarian rejuvenation and folliculogenesis reactivation in peri-menopausal women after autologous plateletrich plasma treatment. Abstracts, ESHRE 32nd Annual Meeting. pp 3-6, Helsinki, Finland. Hum Reprod. (2016) 2016(Suppl. 1):i301. doi: 10.26226/morressier.573c1512d462b80296c98880

28. Sills ES, Rickers NS, L, X, Palermo GD. First data on in vitro fertilization and blastocyst formation after intraovarian injection of calcium gluconateactivated autologous platelet rich plasma. Gynecol Endocrinol. (2018) 34:75660. doi: 10.1080/09513590.2018.1445219

29. Sfakianoudis K, Simopoulou M, Nitsos N, Lazaros L, Rapani A, Pantou A, et al. Successful implantation and live birth following autologous platelet-rich plasma treatment for a patient with recurrent implantation failure and chronic endometritis. In vivo. (2019) 33:515-21. doi: 10.21873/invivo.11504

30. Marini MG, Perrini C, Esposti P, Corradetti B, Bizzaro D, Riccaboni P, et al. Effects of platelet-rich plasma in a model of bovine endometrial inflammation in vitro. Reprod Biol Endocrinol. (2016) 14:58. doi: 10.1186/s12958-016-0195-4

31. McLaren A. Primordial germ cells in the mouse. Dev Biol. (2003) 262:1-15. doi: 10.1016/S0012-1606(03)00214-8

32. Pepling M.E. From primordial germ cell to primordial follicle: mammalian female germ cell development. Genesis. (2006) 44:622-32. doi: $10.1002 /$ dvg. 20258

33. Kaipia A, Hsueh AJ. Regulation of ovarian follicle atresia. Annu Rev Physiol. (1997) 59:349-63. doi: 10.1146/annurev.physiol.59.1.349

34. Jiang JY, Cheung CK, Wang Y, Tsang BK. Regulation of cell death and cell survival gene expression during ovarian follicular development and atresia. Front Biosci. (2003) 8:222-37. doi: 10.2741/949

35. Gracia CR, Shin SS, Prewitt M, Chamberlin JS, Lofaro LR, Jones KL, et al. Multi-center clinical evaluation of the Access AMH assay to determine AMH levels in reproductive age women during normal menstrual cycles. J Assist Reprod Genet. (2018) 35:777-83. doi: 10.1007/s10815-018-1141-5

Conflict of Interest: The authors declare that the research was conducted in the absence of any commercial or financial relationships that could be construed as a potential conflict of interest.

Copyright (C) 2020 Cremonesi, Bonfanti, Idda and Lange-Consiglio. This is an openaccess article distributed under the terms of the Creative Commons Attribution License (CC BY). The use, distribution or reproduction in other forums is permitted, provided the original author(s) and the copyright owner(s) are credited and that the original publication in this journal is cited, in accordance with accepted academic practice. No use, distribution or reproduction is permitted which does not comply with these terms. 